\title{
Pressure Ventilation Increases Brain Vascular Prostacyclin Production in Newborn Pigs
}

\author{
ROBERT MIRRO, CHARLES W. LEFFLER, WILLIAM M. ARMSTEAD, AND DAVID W. BUSIJA \\ Departments of Pediatrics, Obstetrics and Gynecology, and Physiology and Biophysics, Laboratory for Research \\ in Neonatal Physiology, University of Tennessee, Memphis, Memphis, Tennessee 38163
}

\begin{abstract}
Using awake, chronically catheterized newborn pigs, we measured cerebral blood flow (CBF), net cerebral vascular 6-keto-prostaglandin $\mathrm{F}_{1 \alpha}$ production, and cerebral metabolic rate of oxygen $\left(\mathrm{CMRO}_{2}\right)$ during hypercapnia and during hypercapnia at increased mean airway pressure $(\overline{\mathrm{Paw}})$, both before and after treatment with indomethacin. CBF nearly doubled during hypercapnia. The hypercapnia-induced cerebral hyperemia was maintained when Paw was increased from $3 \pm 2$ to $16 \pm 4 \mathrm{~cm} \mathrm{H} \mathrm{H}_{2} \mathrm{O}$ during hypercapnia. Sagittal sinus pressure increased in proportion to the increase in $\mathrm{Paw}$, and cardiac output was unchanged. Net cerebral production of 6-keto-prostaglandin $F_{1 \alpha}$ increased from $9 \pm 1$ to $15 \pm 1 \mathrm{ng} / \mathrm{min} / 100 \mathrm{~g}$ tissue during hypercapnia and increased dramatically to $57 \pm 1$ $\mathrm{ng} / \mathrm{min} / 100 \mathrm{~g}$ when hypercapnia was coupled with an increase in Paw. CMRO ${ }_{2}$ was not changed by either hypercapnia or increased Paw. After indomethacin, CBF decreased and cerebral vasodilation to hypercapnia did not occur. After indomethacin, adding increased Paw during hypercapnia dropped CBF below baseline, adversely affecting $\mathrm{CMRO}_{2}$. These results suggest that cerebral hypercapnic hyperemia requires brain prostanoid production and that when Paw is increased during hypercapnia, the contribution of prostanoids to maintaining CBF is increased. Increasing ventilation pressure during hypercapnia in piglets pretreated with indomethacin compromises CBF sufficiently to reduce $\mathrm{CMRO}_{2}$. (Pediatr Res 28: 609612, 1990)
\end{abstract}

\section{Abbreviations}

CBF, cerebral blood flow

6-keto-PGF $\mathrm{F}_{\alpha \alpha}$, 6-keto-prostaglandin $\mathrm{F}_{1 \alpha}$ $\mathrm{CMRO}_{2}$, cerebral metabolic rate of oxygen Paw, mean airway pressure

SSP, sagittal sinus pressure

Prostanoids are an important component of the control of neonatal cerebral hemodynamics (1). For example, changes in cerebral vascular tone in response to hypercapnia $(2,3)$, hypotension (4), and the actions of several neurotransmitters, including norepinephrine (5), acetylcholine (6), and histamine (7), are dependent on prostanoid production. In previous studies, we have also shown that periarachnoid cerebrospinal fluid prostanoids are increased during positive pressure ventilation (8) and that cyclooxygenase inhibition during pressure ventilation restricts CBF (9).

Received May 21, 1990; accepted August 3, 1990.

Correspondence: Robert Mirro, M.D., Newborn Center, 853 Jefferson Avenue, Room 201, Memphis, TN 38163.

Supported by grants from the National Institutes of Health and a Clinical Investigator Award from the National Institutes of Health (R.M.).
Hypercapnia is one of the clinical conditions that often necessitates a change in ventilator management. Either by increasing peak inspiratory pressure and/or end expiratory pressure or by increasing ventilation rate, the clinician will often treat hypercapnia with an increase in Paw. The purpose of these experiments was to study the role of brain vascular prostacyclin production in maintaining cerebral perfusion during hypercapnia and increased ventilation pressure.

\section{MATERIALS AND METHODS}

All protocols were approved by the Animal Care and Use Committee of the University of Tennessee, Memphis.

Animal preparation. Three polyurethane catheters were placed in each of 14 newborn pigs (1.9-2.4 kg, 1-2 d old) under general (halothane, $\mathrm{N}_{2} \mathrm{O}$, oxygen) anesthesia. Two catheters were placed into the dorsal aorta via the umbilical arteries, and a third catheter was placed in the left ventricle via the right carotid artery. From previous studies $(2,10)$, we have shown that ligation of one carotid artery does not alter CBF or cerebrovascular responsiveness under a variety of conditions. Catheters were then tunneled s.c. to the flank, exteriorized, and placed in a cloth pouch. After surgery, the animals were given penicillin and gentamicin and placed in a heated incubator until fully awake. They were then returned to their cages and provided with a continual supply of pig milk substitute. Experiments were performed on the next day.

Experimental protocol. Piglets were intubated with a $3.0-\mathrm{mm}$ (inner diameter) straight, uncuffed endotracheal tube, and a feeding tube was passed into the stomach. Piglets were given $10-$ $15 \mathrm{~mL}$ of pig milk substitute during long wait periods. Animals were placed into cloth slings with an overhead radiant heater to keep body temperature at $37.5-38.5^{\circ} \mathrm{C}$. An arterial catheter was connected to a pressure transducer for continual monitoring of arterial blood pressure, Pressure ventilation was provided by a standard, time-cycled, pressure-limited infant respirator (Bourns BP 200, Bourns Life Systems, Riverside, CA) and airway pressure monitored at the proximal end of the endotracheal tube. SSP was measured, and sagittal venous blood was taken through a 20-gauge Teflon catheter that was placed (under local anesthesia) in the sagittal sinus.

Beginning at a minimal $\mathrm{Paw}\left(3 \pm 2 \mathrm{~cm} \mathrm{H} \mathrm{H}_{2} \mathrm{O}\right.$, inspiratory time $=0.5 \mathrm{~s}$, respiratory rate $=5-10)$, arterial blood was taken for $\mathrm{pH}, \mathrm{PO}_{2}, \mathrm{PCO}_{2}, \mathrm{O}_{2}$ content, and plasma 6-keto-PGF $\mathrm{P}_{1 \alpha}$. Sagittal sinus blood was also taken for $\mathrm{O}_{2}$ content and plasma 6-keto$\mathrm{PGF}_{1 \alpha}$. Cardiac output and $\mathrm{CBF}$ were then measured using radioactive microspheres. A 10 -min period of arterial hypercapnia (induced by breathing $10 \% \mathrm{CO}_{2}, 21 \% \mathrm{O}_{2}, 69 \% \mathrm{~N}_{2}$ ) followed, and the measurements listed above were repeated. While still hypercapnic, $\mathrm{Paw}$ was increased (by increasing both peak inspiratory and end expiratory pressures) for $10 \mathrm{~min}$ to a level $(16 \pm$ $4 \mathrm{~cm} \mathrm{H} \mathrm{H}_{2} \mathrm{O}$ ) that we have previously demonstrated increases SSP without decreasing cardiac output $(8,10)$. The same measurements were then repeated, and the Paw was returned to the 
previous baseline level. Indomethacin $(5 \mathrm{mg} / \mathrm{kg}$ intraarterially) was given, and a 45 -min period was allowed for stabilization. The protocol was then repeated with the same three experimental conditions (i.e. normocapnia/low Paw, hypercapnia/low Paw, and hypercapnia/high Paw).

Time control animals. Two animals were studied as time controls to insure reproducibility of responses to hypercapnia and increased Paw. These animals followed the same experimental protocol as above except that saline was administered instead of indomethacin. In these animals, CBF continued to respond the same (increased with hypercapnia from $82 \pm 11$ to $156 \pm 13$ $\mathrm{mL} / \mathrm{min} / 100 \mathrm{~g}$ tissue; with hypercapnia and high Paw, to $171 \pm$ $15 \mathrm{~mL} / \mathrm{min} / 100 \mathrm{~g}$ ) both before and after saline.

Blood chemistry determinations and cerebral $\mathrm{O}_{2}$ consumption. Arterial $\mathrm{pH}, \mathrm{PO}_{2}$, and $\mathrm{PCO}_{2}$ were determined using a blood gas analyzer (Instrumentation Laboratory, Inc., Lexington, MA). An American Optical Reflection Oximeter (American Optical Corp., Buffalo, NY), corrected to newborn pig blood, was used to determine percent saturation of the $\mathrm{Hb}$ in arterial and sagittal sinus blood. Blood $\mathrm{Hb}$ was determined using a Reichert Hemoglobinometer (Reichert Scientific Instruments, Buffalo, NY). The capacity of the $\mathrm{Hb}$ was assumed to be $1.39 \mathrm{~mL} \mathrm{O} / \mathrm{g}$ of $\mathrm{Hb}$. Blood oxygen content then was calculated as: $\mathrm{g} \mathrm{Hb} / 100 \mathrm{~mL} \times$ $1.39 \mathrm{~mL} \mathrm{O}_{2} / \mathrm{g} \mathrm{Hb} \times$ percent saturation of $\mathrm{Hb}$ with $\left.\mathrm{O}_{2}\right)+$ dissolved $\mathrm{O}_{2}$ ( $\mathrm{mL} \mathrm{O} / 100 \mathrm{~mL}$ blood). The arterial-venous oxygen content difference is the arithmetic difference of these two values. $\mathrm{CMRO}_{2}$ was calculated as (arterial $\mathrm{O}_{2}$ content - venous $\mathrm{O}_{2}$ content) $\times \mathrm{CBF} \div 100$.

Microsphere determination of cardiac output and $C B F$. Approximately $100000015-\mu \mathrm{m}$ radioactive microspheres $\left({ }^{46} \mathrm{Sc}\right.$, ${ }^{95} \mathrm{Nb},{ }^{103} \mathrm{Ru},{ }^{113} \mathrm{Sn}$, and ${ }^{57} \mathrm{Co}$ ) were counted in a gamma counter before injection into the left ventricle. Withdrawal of reference blood through an aortic catheter began $15 \mathrm{~s}$ before microsphere injection and continued for $2 \mathrm{~min}$ after the injection. After the experiment, the animal was killed and the brain removed and cut into regions. Determination of radioactivity was done by differential spectroscopy. Cardiac output was calculated as reference withdrawal rate $\times$ counts injected $\times$ counts in reference withdrawal ${ }^{-1}$. Cerebral and regional blood flow at the time that the microspheres were injected was calculated by using the formula: $\mathrm{Q}=\mathrm{C} \times \mathrm{R} \times \mathrm{CR}-1$, where $\mathrm{Q}=$ blood flow in $\mathrm{mL} / \mathrm{min}$ $\times 100 \mathrm{~g}, \mathrm{C}=$ counts $/ 100 \mathrm{~g}$ tissue, $\mathrm{R}=$ rate of withdrawal of reference blood sample in $\mathrm{mL} / \mathrm{min}$, and $\mathrm{CR}=$ total counts in reference arterial blood sample.

Brain prostacyclin production measurements. Paired plasma samples from the aorta and sagittal sinus were measured before indomethacin was given by previously described RIA techniques (7). Briefly, antibodies to 6-keto-PGF ${ }_{1 \alpha}$ (hydrolysis product of prostacyclin) were produced in rabbits immunized with 6-keto$\mathrm{PGF}_{1 \alpha}$ coupled to thyroglobulin. Cross-reactivity of the antibodies with other eicosanoids was $<1 \%$. Further, target ligands are not displaced from the antibodies by arachidonic acid $(20 \mu \mathrm{g} /$ $\mathrm{mL}$ ); 5-12-hydroxyeicosatetraenoic acid or 15-12-hydroxyeicosatetraenoic acid $(\mu \mathrm{g} / \mathrm{mL}) ; \mathrm{LTB}_{4}, \mathrm{LTC}_{4}$, or $\mathrm{LTE}_{4}(5 \mu \mathrm{g} / \mathrm{mL})$; or lipoxin $\mathrm{A}_{4}$ or lipoxin $\mathrm{B}_{4}(10 \mathrm{ng} / \mathrm{mL})$. Assays were performed in Tris buffer against a matrix of plasma from which prostanoids had been removed. Free fraction was separated from the bound fraction by adsorbing the unbound ligand on activated charcoal. Data were handled by computer with determination of 2 nd order regression of tracer bound to antibody against labeled prostanoid by method of least squares.

Brain 6-keto-PGF $F_{1 \alpha}$ production was calculated as (sagittal sinus concentration - arterial concentration) $\times \mathrm{CBF}$. Values are reported as $\mathrm{ng} / \mathrm{min} / 100 \mathrm{~g}$ tissue.

Statistical analysis. All values are presented as mean \pm SEM. Comparisons were made using a one-way analysis of variance with replications and a Scheffe's post hoc test. A $p<0.05$ was required for significance.

\section{RESULTS}

Table 1 summarizes the cardiac output, blood pressure, cerebral venous pressure, and arterial blood gas/pH data from these experiments. Cardiac output and arterial blood pressure were unchanged during the study. SSP increased significantly when $\mathrm{Paw}$ was raised. Arterial blood gases/pH reflect the respiratory acidosis created while the animals were breathing the hypercapnic gas mixture. $\mathrm{Hb}$ was $8.1 \pm 1.6 \mathrm{~g} / \mathrm{dL}$ during these experiments.

Figure 1 shows the brain vascular 6-keto-PGF ${ }_{1 \alpha}$ production before indomethacin. The hypercapnic increase in 6-keto-PGF $1 \alpha$ is dramatically accentuated at the high Paw. All arterial and SSP plasma tested had nondetectable levels of 6-keto-PGF $F_{1 \alpha}$ after indomethacin.

Figure 2 shows the changes in CBF during these experiments. Hypercapnia caused significant hyperemia that was maintained when the Paw was raised. After indomethacin, baseline CBF decreased by $40 \%$, and hypercapnia did not increase CBF. When the $\mathrm{Paw}$ was raised during hypercapnia after indomethacin, CBF fell to below the corresponding normocapnic period.

Figure 3 shows that $\mathrm{CMRO}_{2}$ was not changed by hypercapnia, increased $\mathrm{Paw}$, or indomethacin alone but was decreased significantly with hypercapnia and increased $\mathrm{Paw}$ after indomethacin.

\section{DISCUSSION}

We have previously demonstrated the importance of brain prostanoid production during stress situations $(1,2,4)$, including positive pressure ventilation $(8,9)$. Our present data further support the role of prostanoid production during hypercapnic hyperemia and pressure ventilation in newborn pigs. $\mathrm{CMRO}_{2}$ as well as CBF were adversely affected only after indomethacin by increasing $\overline{\mathrm{aw}}$ during hypercapnic hyperemia. Our present data strongly suggest that brain prostanoid production is responsible for dilating brain vessels and maintaining CBF during pressure ventilation.

Prostanoid production through cyclooxygenase appears to be a significant component of CBF regulation in newborn pigs. When prostanoid production is inhibited by either indomethacin (4) or ischemia/reperfusion (11), subsequent stresses to the cerebral circulation are less well tolerated. From our present data, this includes the stress of increasing Paw during hypercapnic hyperemia.

Although all four of the prostanoids measured under the cranial window (6-keto- $\mathrm{PGF}_{1 \alpha}, \mathrm{TxB}_{2}, \mathrm{PGE}_{2}$, and $\mathrm{PGF}_{2 \alpha}$ ) increased with increasing $\mathrm{Paw}(8)$, only prostacyclin and $\mathrm{PGE}_{2}$ are vasodilators. Prostanoids present in CNS may be produced by the blood vessels, autonomic nerves associated with these vessels, or by brain parenchyma. Available evidence from other species would suggest that prostacyclin is preferentially produced by the brain vessels (12). Prostacyclin, as the predominant vasodilator made by the vascular endothelium, may be a likely candidate to directly oppose a pressor influence. Our study therefore focused on vascular prostacyclin production by measuring net brain vascular (vein-artery) 6-keto-PGF ${ }_{1 \alpha}$. The increase in 6-keto$\mathrm{PGF}_{1 \alpha}$ seen in our study may have been stimulated by several forces acting on the endothelium, including direct wall stress or sheer forces from venous congestion or from an initial decrease in vessel flow seen when venous pressure was raised.

During positive pressure ventilation, cerebral venous pressure increases and $\mathrm{CBF}$ is maintained (8), indicating that cerebral vascular resistance decreases. When indomethacin is administered in a dose sufficient to inhibit prostanoid production on the parenchymal side of the blood-brain barrier, pial arterioles paradoxically constrict (8). Constriction in response to an increased Paw after indomethacin implies that prostanoids are working to counteract a constrictor agent, such as thromboxane, acetylcholine, catecholamines, norepinephrine, or $\beta$-endorphin. Thromboxane can be discounted because as a cyclooxygenase product it would also be eliminated by indomethacin. Acetylcholine, 
Table 1. Cardiac output, mean arterial blood pressure, mean SSP, and arterial blood gases/pH*

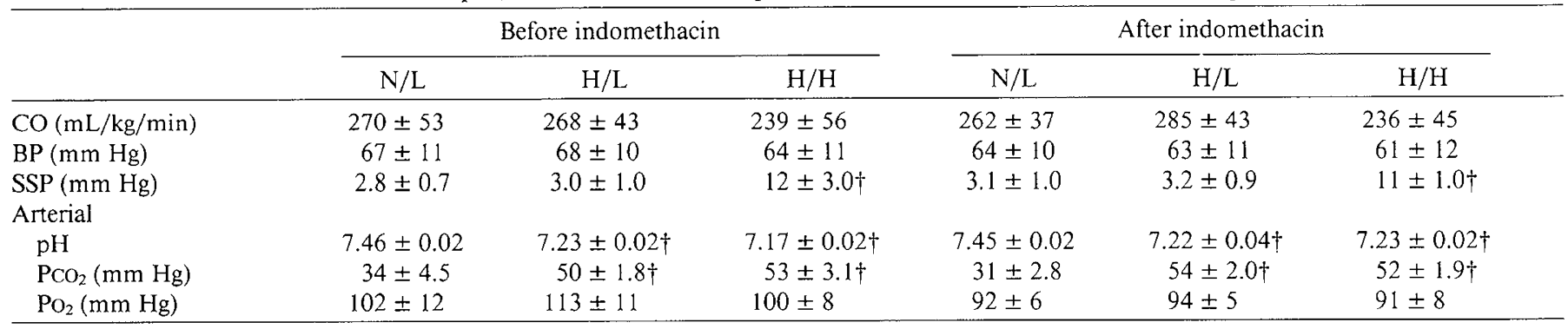

* Abbreviations: N/L, normocapnia/low Paw; H/L, hypercapnia/low $\mathrm{Paw} ; \mathrm{H} / \mathrm{H}$, hypercapnia/high Paw; CO, cardiac output; BP, mean arterial blood pressure. $n=14$; values are means \pm SEM.

$\dagger p<0.05$ vs corresponding $\mathrm{N} / \mathrm{L}$.

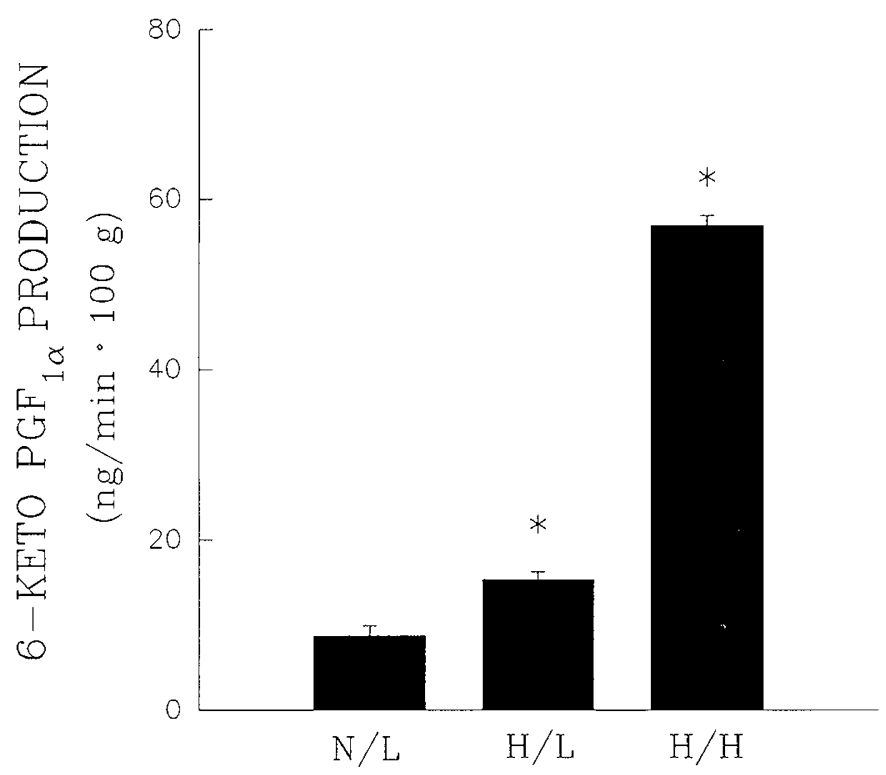

Fig. 1. Brain vascular 6-keto-PGF ${ }_{1 \alpha}$ production before indomethacin $(n=4)$. Values are means \pm SEM. N/L, normocapnia/low Paw; H/L, hypercapnia/low $\overline{\mathrm{Paw}}$; and $\mathrm{H} / \mathrm{H}$ hypercapnia/high $\overline{\mathrm{Paw}}$. ${ }^{*}$, statistically different $(p<0.05)$ from corresponding $\mathrm{N} / \mathrm{L}$ value.

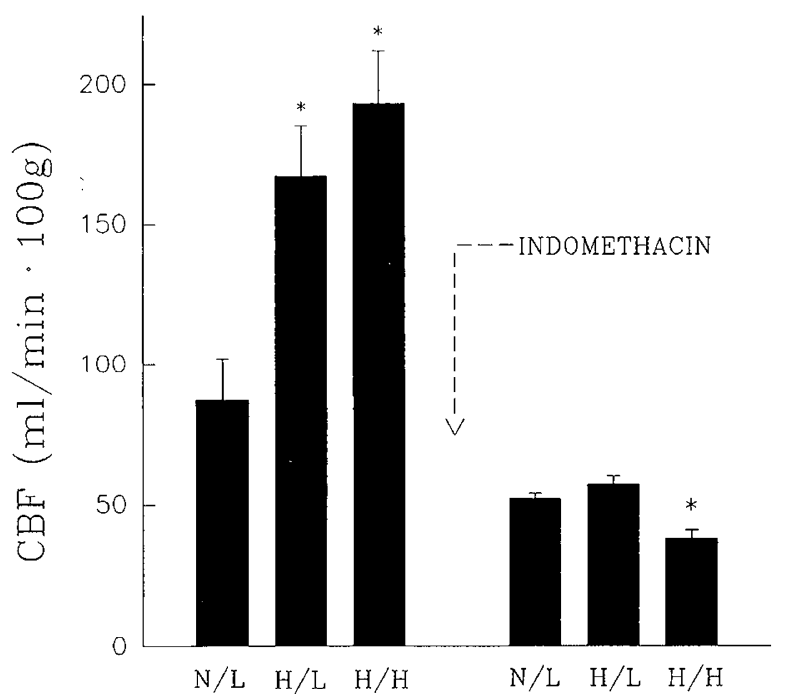

Fig. 2. $\mathrm{CBF}$ at the six time periods studied $(n=14)$. N/L, normocapnia/low Paw; $\mathrm{H} / \mathrm{L}$, hypercapnia/low $\mathrm{Paw}$; and $\mathrm{H} / \mathrm{H}$, hypercapnia/high Paw. Values are means \pm SEM. ${ }^{*}$, statistically different $(p<0.05)$ from corresponding $\mathrm{N} / \mathrm{L}$ value.

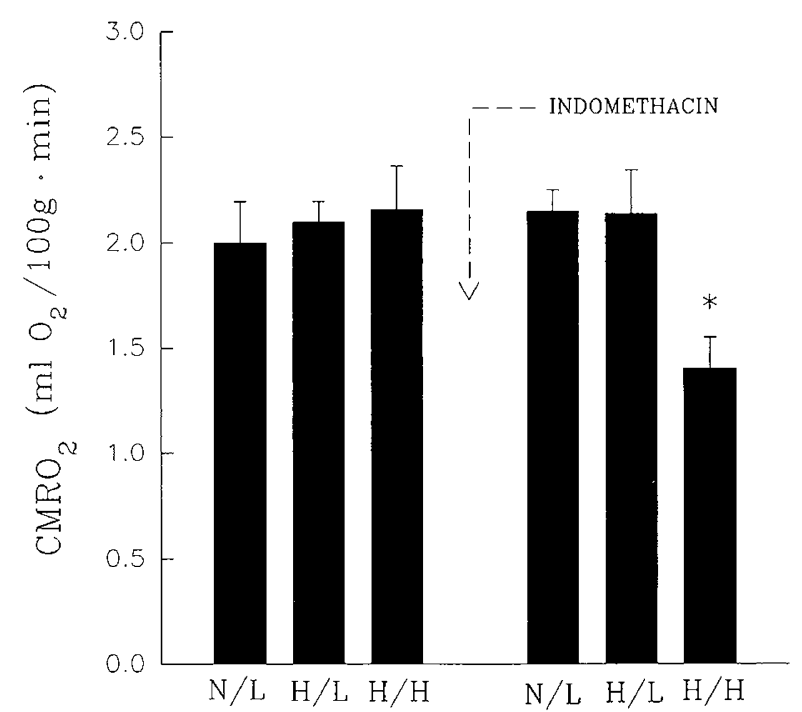

Fig. 3. $\mathrm{CMRO}_{2}$ at the six time periods studied $(n=14)$. N/L, hypercapnia/low $\mathrm{Paw} ; \mathrm{H} / \mathrm{L}$, hypercapnia/low $\mathrm{Paw}$; and $\mathrm{H} / \mathrm{H}$, hypercapnia/ high $\mathrm{Paw} .{ }^{*}$, statistically different $(p<0.05)$ from corresponding $\mathrm{N} / \mathrm{L}$ value.

which is a constrictor agent in the cerebral circulation of the piglet, requires prostanoids to exert its pressor action (6). Catecholamines also are a possibility, especially in light of previous work that has shown that indomethacin does not alter circulating catecholamines in asphyxiated newborn pigs (13). The constrictor effects of norepinephrine are attenuated by prostanoids (14), so that increased sympathetic tone induced by hypercapnia and increased Paw would be expected to have greater effects on pial arterioles after hypercapnia. Finally, we have shown that $\beta$ endorphin-induced constriction is potentiated by indomethacin, suggesting that the pressor effect of this opioid is attenuated by prostanoids (15).

$\mathrm{CMRO}_{2}$ is adversely affected by the combination of hypercapnia and high $\mathrm{Paw}$ after indomethacin administration. In previous experiments, however, $\mathrm{CMRO}_{2}$ was maintained despite the decrease in CBF observed when indomethacin was given at a high Paw (9). The only difference between our present experiments and the previous data is the addition of respiratory acidosis. Other investigators $(3,16)$ have shown that acidosis plays an important role in the cerebral vasodilation that results from hypercapnia. Cerebral vasodilation from acidosis, however, is inhibited by indomethacin (3), further suggesting that hypercapnia vasodilates through a prostanoid-dependent system.

The functional significance of prostanoids during hypercapnia and increased $\mathrm{Paw}$ is best appreciated when compared with the role that prostanoids play in maintaining newborn $\mathrm{CBF}$ during hypotension (4). In both cases (high $\mathrm{Paw}$ and hypotension), there is a decreased cerebral perfusion pressure requiring the brain vasculature to vasodilate to defend brain flow. In either case, the 
inhibition of the prostanoid system has an adverse effect on brain oxygen delivery. Our present study indicates that increasing Paw during hypercapnia is not detrimental when the prostanoid system is intact. However, previous treatment with indomethacin compromises $\mathrm{CBF}$ sufficiently to compromise $\mathrm{CMRO}_{2}$ when $\mathrm{Paw}$ is increased during hypercapnia.

\section{REFERENCES}

1. Leffler CW, Busija DW 1987 Arachidonic acid metabolites and perinatal cerebral hemodynamics. Semin Perinatol 11:31-42

2. Leffler CW, Busija DW, Fletcher AM, Beasley DG, Hessler JR, Green RS 1985 Effects of indomethacin upon cerebral hemodynamics of newborn pigs. Pediatr Res 19:1160-1164

3. Wagerle LC, Mishra OP 1988 Mechanism of $\mathrm{CO}_{2}$ response in cerebral arteries of the newborn pig: role of phospholipase, cyclooxygenase and lipoxygenase pathways. Circ Res 62:1019-1026

4. Leffler CW, Busija DW, Beasley DG, Fletcher AM 1986 Maintenance of cerebral circulation during hemorrhagic hypotension in newborn pigs: role of prostanoids. Circ Res 59:562-567

5. Busija DW, Leffler CW 1987 Eicosanoid synthesis elicited by norepinephrine in piglet parietal cortex. Brain Res 403:243-248

6. Busija DW, Wagerle LC, Pourcyrous M, Leffler CW 1988 Acetylcholine dramatically increases prostanoid synthesis in piglet parietal cortex. Brain Res 439:122-126
7. Mirro R, Busija DW, Armstead WM, Leffler CW 1988 Histamine dilates pial arterioles of newborn pigs through prostanoid production. Am J Physiol 254:H1023-H1026

8. Mirro R, Armstead WM, Busija DW, Green R, Leffler CW 1987 Increasing ventilation pressure increases cortical subarachnoid CSF prostanoids in newborn pigs. Pediatr Res 22:647-650

9. Mirro R, Leffler CW, Armstead W, Beasley DG, Busija DW 1988 Indomethacin restricts cerebral blood flow during pressure ventilation of newborn pigs. Pediatr Res 24:59-62

10. Mirro R, Busija DW, Green R, Leffler C 1987 Relationship between mean airway pressure, cardiac output, and organ blood flow with normal and decreased respiratory compliance. J Pediatr 111:101-106

11. Leffler CW, Beasley DG, Busija DW 1989 Cerebral ischemia alters cerebral microvascular reactivity in newborn pigs. Am J Physiol 257:H266-H271

12. Groehlert UG, Ying Kin NMK, Wolfe LS 1981 Biosynthesis of prostacyclin in rat cerebral microvessels and the choroid plexus. J Neurochem 36:11921201

13. Green RS, Leffler CW, Busija DW, Fletcher AM, Beasley DG 1987 Indomethacin does not alter the circulating catecholamine response to asphyxia in the neonatal piglet. Pediatr Res 21:534-537

14. Busija DW, Leffler CW, Wagerle C 1985 Responses of newborn pig pial arteries to sympathetic nervous stimulation and exogenous norepinephrine. Pediatr Res 19:1210-1214

15. Armstead WM, Mirro R, Busija DW, Leffler CW 1990 Prostanoids modulate opioid cerebrovascular responses in newborn pigs. J Pharm Exp Ther (in press)

16. Kontos HA, Raper AJ, Patterson Jr JL 1977 Analysis of vasoactivity of local $\mathrm{pH} \mathrm{pCO}_{2}$, and bicarbonate on pial vessels. Stroke 8:358-360 